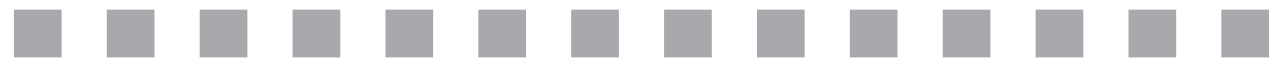

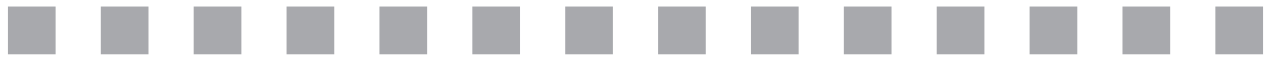



Central European Journal of Communication vol. 11, no 1 (20), Spring 2018 (C) for this edition by CNS 


\title{
Established media still matter
}

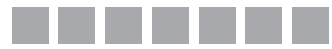 \\ Interview with Prof. Dr. Christina Holtz-Bacha \\ Professor of Communications at Friedrich-Alexander-University \\ Erlangen-Nuremberg, Germany \\ DOI: 10.19195/1899-5101.11.1(20).7
}

Quite recently I read a report on the influence of fake news on voting decisions and there was something interesting that contrary to the United States or contrary to Great Britain public opinion in Germany has somehow not been caught up in a fake news industry trap. One of the conclusions speculated, that it was because of good journalism and high trust in traditional media. How would you comment? Do you agree? Is this only a German phenomenon?

I think I know the report you're referring to and I have seen the figures that came out of the comparison to the US, France, UK and Germany and there was one explanation that the credibility of traditional media is higher than in other countries, particularly higher than in the US. It might be a reason for a low flow of fake news and low influence of fake news. In fact, it has not been much although there were great fears that there would be a lot of social bots going around and fake news. At the end not much happened, but I'm not so sure if I think about the US election. Only now it turns out that there was a lot going on in the US and much more than we knew at the time the election campaign was on. Maybe after some time we will know more what was going on in Germany. But yes, there definitely is a difference between the German system and the US. The credibility of traditional media is higher, and the traditional media are quite influential because many people use them not on paper but use them on the internet. So, their influence is substantial. That may indeed be a reason for the low influence of fake news. Also, there was a lot of fear that there would be a danger of social bots going around, but established parties said very early on that they won't use them. It was only the AfD that announced they would use it. I don't know about the extent to which they really used bots. So maybe people were also sensitized through the phenomenon and maybe took care. The use of social media is much lower in Germany than in the US. Twitter, for example, is only used by political actors and journalists, so the distribution and penetration of Twitter is much 
lower than in the US, and even Facebook is not used as much as in the US. Therefore, the possibilities to distribute fake news and the use of bots to reach people is much lower.

Do you consider it generational? Because there seems to exist a dependency that the younger you are the more you use social media, and the less you are stuck to political news and political activities and then, unfortunately, it might end up with a lower turnout with a lower consciousness of what is good, wrong, what is true what is fake etc.?

It is a generational question. Of course, social media is something that particularly the young generation uses, but still social media have been around for some time now and maybe people as they get older turn away from social media. I have seen data comparing the youngest generation and those aged 30-49. They have been raised on social media and they got used to them but there is still quite a difference between the youngest generation and the next groups. So, it seems as if people when getting older return to the established media again. I don't know whether we really realize what is going on and how the development is going with social media.

Nowadays, we surprisingly observe an increasing number of comments that social media became not a chance to include more people and to let them engage and share their opinion, but perhaps a threat to democracy. And it's been only ten years since Barack Obama had used social media in political campaigning to such a great extent. That is the reason that social media are used badly on one hand and on the other because of a low political consciousness of young people. Would you agree with such a statement?

First of all, in 2008 the media went crazy about Obama's campaign and the use of social media. Political actors were happy about a new channel that allows them to circumvent the journalistic media and to avoid uncomfortable questions. It turned out that social media did not replace traditional media. It is an additional campaign channel and there is also a difference between receiving messages through social media and political actors using them. It turns out that it does not necessarily mean more activity on the part of the electorate, of the voters. They receive news and electoral messages via social media, but they do not necessarily engage themselves, so that is quite a difference. If we look at the most recent presidential election in the US, of course social media played a major role but political advertising on television was still very important and the spending again was gigantic. So, it is an additional campaign channel but does not replace traditional media. Also, what we can see from research in different countries, the great advantage of social media and web 2.0 is the interactivity but it is not used. 
Talking of the US, what do you think about so-called Americanization and its influence on electoral practices? This is not only a matter of the most popular online communication platforms like Facebookand Twitter, but it also seems to be an adoption of the whole model of campaigning or at least, as some scholars claim, European "shopping" in the US. There were also early critics, like Negrine and Papathanassopoulos, who argued that it is rather because of various modernization processes, that the campaigns tend to change. What is your point?

I am very happy that you asked me about Americanization, because long ago I decided not to use this term anymore. I don't think it fits. The situation in the United States is so different compared to European countries, so I decided to no longer speak about and use the term 'Americanization' and instead speak of professionalization. I think what is happening is an ongoing process. An ending-ization stands for a dynamic process which has not come to an end and I think even without the US model many features that we observe in European campaigns would have happened, would have occurred even without a model. That's why I use the term professionalization. It is an ongoing process and it has started decades ago. Campaigns after the war were professional for their time. Of course, with the technical development and new tools professionalization went on and took in new possibilities for campaigning. I also understand professionalization in a very broad sense. It's not only that campaigns as such are professionalizing. Candidates also have to professionalize, within the trend of personalization, which I see a bit differently compared to other authors. Individual politicians have become or are very important in campaigns, even in Europe where we mostly have parliamentary systems. Individual candidates and politicians are important and that means that they also must adapt to the challenges, to technical development and political development. Professionalization means to adapt to the situation of the campaign and most importantly to the economic situation of the country at the time of the campaign. So, a campaign this year is probably different from what is going to happen after the term, in four or five years.

So, your perspective, if I understood it correctly, not only refers to the political marketing paradigm, but also to something broader.

Yes, it's broader. It also challenges the media system, the journalists, because they have to deal with the professionalization of campaigns. Of course professional campaigners will do their best and try to make sure the media will transfer the political messages unchanged while journalists and the media are trying to keep their critical role, to make comments, to play an influential role in campaigning. So, the professionalization of political actors challenges journalists and they have to deal with it too. 
Some researchers believe that the professionalization process started mainly due to the mediatization of politics. Because of the televised skills required from politicians, because of the media expectations aimed at leaders who were supposed to easily go for live interview and so on and so forth. So perhaps it is rather the media that shape political actors, not vice versa?

What do we expect the media to do, what role should media play in campaigns? We expect them to ask questions, to be critical, to make it transparent how politicians present themselves, what they do or how they stage their campaign. I think that is what many politicians complain about. It is not comfortable for politicians if the media ask uncomfortable and difficult questions and they ask questions about issues, they should ask questions about issues, and are not content with the staging of political actors and that's what we should expect the media and journalists to do.

And what about the methodological aspect of professionalization? You presented it in terms of a qualitative approach, what about a quantitative approach? Can we measure it? There were attempts and proposals to measure the level or scope of professionalization, but all in all there hardly exists one complex system of parameters. Do you find it measurable? Is this discussion over?

It's very difficult and I have criticized attempts to come up with measures of professionalization. If we develop a measure it must allow comparisons over time, because professionalization, like I said, is an ongoing process. So, if we want to determine whether professionalization is increasing we need something that allows us to compare election campaigns, let's say eight years ago and the current election. That is almost impossible. For instance, if a measure includes the usage of social media, it does not work, because we didn't have them eight or twelve years ago. So, that cannot be an indicator of professionalization. I must admit, I don't have one, but what we need is a measure that is dynamic as is the process of professionalization itself. I would say there are several indicators we can use. I always think about the German national elections in 1949, the first ones in the newly founded Federal Republic. The Social Democrats had professional advisers, who helped with the campaign advertising. After that, in following elections, it was the Christian Democrats who hired advertising agencies and marketing experts to an increasing extent. This is an example of one indicator - hiring expertise from outside the party. Then of course it's different campaign tools, how they are used. Professionalization is a process that is not only increasing, it can decrease. Once again, an example from Germany. The Social Democratic Party (SPD) had a highly professional campaign in 1998. The campaign started more than one year before election day. Since then they have never run again such a professional campaign. Obviously, it depends very much on the people who are in charge, on the advisers, on the candidates. In 1998, it was Gerhard Schroeder, a very media savvy politician, but after him the Social Demo- 
cratic candidates were not as comfortable dealing with the media as Schroeder was. So, candidates must be professional as well. We can also observe how Angela Merkel has professionalized since she ran for the first time. She was not very good in the 2005 campaign when she ran for the first time. If we compare her advertising on TV, we can see a development and how she adapted to the challenges and necessities of modern campaigning.

What could you tell, perhaps younger scholars, about the idea of longitudinal research? There are many processes we neither can easily measure, nor we can compare, because things change over time. The right choice is then to focus on single elections or election cycles or go longitudinal? Or perhaps to try both?

Definitely longitudinal. It's more complicated, but if we want to observe a process that is going on for quite a long time, which can, as I said, increase or decrease, we have to go longitudinal. That probably means we cannot use quantitative measures only but maybe we have to add some qualitative aspects or factors. That happens in other fields as well. I'm thinking of the research we have done on electoral posters. It's visual communication. Visuals are very difficult to be compared and analysed only quantitatively. You have to get the meaning of a slogan or of an image. We usually add qualitative perspectives.

In a Handbook of Political Advertising, edited quite recently, you compared different legal frameworks of political advertising. You referred mainly to traditional media systems with various solutions adopted, like granting parties free air time or letting them purchase air time on tv and radio. Do you think there needs to be a regulation on social media or regulatory policy, which defines boundaries of online campaigning, e.g., campaign spending limits, the ways you can sponsor political messages etc.?

Political actors of course use the possibility to advertise online and that gives them many more opportunities than television, but I see many problems with regulation of the internet and social media. Whatever you do risks interfering with freedom of opinion, freedom of the press. I mean, what we have seen recently, the discussions about regulating hate speech on social media. In Germany, there is now a new law, it is difficult to come up with regulations and German law was much criticized. I don't have any idea how we can solve that problem. It's much easier of course to regulate television than online communication.

What about spending, because it also appears to be a problem?

It is indeed a problem. We have very different approaches to that. There are several countries that regulate and limit spending in campaigns. I think that it is maybe 
a good idea, because there are major disadvantages for smaller parties, for new parties coming up and for candidates coming from outside the political system. It depends very much on the different systems of party financing.

Established, institutional media are often obliged to report how much money was spent on paid political advertising, whereas foreign companies running online media platforms try to avoid sharing the same information. It opens the door to covert financing and creates a relatively low transparent communication space.

In traditional media there are some country differences, because thinking of Germany in public service media there is nothing to report, because they just transmit the advertising, there is no money being spent there. The same is true for commercial television stations, they don't have anything to report. There is no institution to report to, so I think there might be differences. In some countries we have an electoral commission, institutions, but I come from a country where there is not much regulation for election campaigns anyway. I do understand your question, but it cannot be answered so easily.

\section{Thank you}

Dr. Christina Holtz-Bacha is Professor of Communications at Friedrich-Alexander-Universität Erlangen-Nürnberg, Germany. Before she went to Nuremberg, she taught at the universities in Mainz, Bochum, and Munich. She was a Visiting Scholar at the University of Minnesota in Minneapolis (1986), a Research Fellow at the Shorenstein Center, Harvard University (1999), a Guest Researcher at the Political Communication Center at the University of Oklahoma in Norman $(1995 ; 1996)$ and at the University of Gothenburg, Sweden (2011). She is presently Chair of the Political Communication Research Section of IAMCR. She is a co-editor of the German communication journal Publizistik and a member of the editorial boards of several international journals. Her main research interests are in political communication, media systems, and European media policy. Among her most recent publications are The Routledge Handbook of Political Advertising (2017, edited with Marion Just), Political Campaigning in the Public Space. Election Posters around the Globe (2017, edited with Bengt Johansson) and Handbook on Political Populism (2017, edited with Reinhard Heinisch and Oscar Mazzoleni) and Political Advertising in the 2014 European Parliament Elections (2017, edited with Edoardo Novelli and Kevin Rafter). 


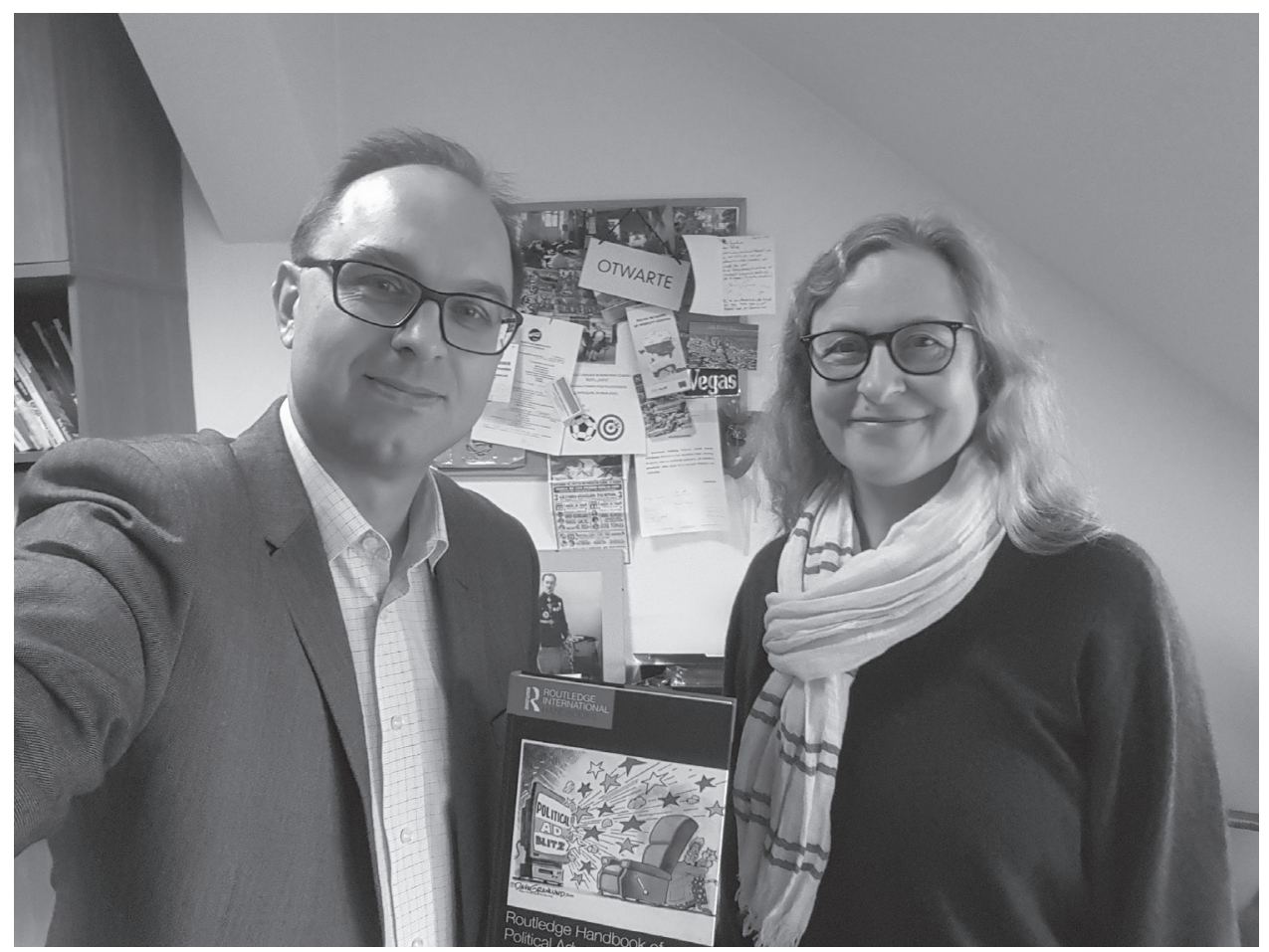

Christina Holtz-Bacha and Michał Jacuński in Wrocław (November 2017)

Source: Michał Jacuński.

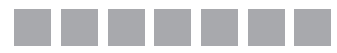

Prof. Dr. Christina Holtz-Bacha was interviewed by Michał Jacuński in November 2017. 